\title{
Analisis dan Pengembangan Pipeline Cloth Simulation pada Produksi Animasi 3D di MSV Studio
}

\author{
Cloth Simulation Pipeline Analysis and Development in 3D Animation \\ Production at MSV Studio
}

\author{
Ardian Yuligar Safagi*1, Kusrini ${ }^{2}$, Hanif Al Fatta ${ }^{3}$ \\ 1,2,3 Universitas Amikom Yogyakarta \\ E-mail: *1ardianyuligars@amikom.ac.id, ${ }^{2}$ kusrini@amikom.ac.id, ${ }^{3}$ hanif.a@amikom.ac.id
}

\begin{abstract}
Abstrak
Pengaruh penerapan pipeline dalam sebuah industry animasi $3 d$ sangat mempengaruhi produksi animasi agar maksimal. Dalam masing-masing divisi juga terdapat pipeline yang digunakan contohnya pipeline pada divisi cloth simulation. Pada MSV Studio pipeline simulasi yang diterapkan di divisi cloth simulation masih terdapat beberapa kendala pada saat produksi. Cara kerja pipeline yang sudah ada yaitu pada saat proses pengecekan data asset yang masih manual antara Sceneres dan Renderes yang diperlukan untuk simulasi cloth masih sering terjadi kesalahan seperti human error dan set up cloth masih dilakukan disetiap shot. Dari masalah tersebut diusulkan untuk dilakukan pengembangan pipeline cloth simulation agar bisa meminimalisir kesalahan dan menghemat waktu pengerjaan. Hasil dari produksi film animasi sangat dipengaruhi oleh pipeline yang digunakan dalam produksi tersebut. Studi ini memberikan gambaran bagaimana sebuah pipeline ikut andil besar dalam sebuah hasil dari produksi film animasi 3D terutama dalam masalah waktu. Pada akhirnya studi ini dapat menjadi acuan dalam pembuatan sebuah pipeline film animasi khususnya pada divisi cloth simulation.
\end{abstract}

Kata Kunci - pipeline, cloth simulation, animasi 3D

\begin{abstract}
The effect of pipeline application in a $3 D$ animation industry greatly influences the production of animation for maximizing. In each division. there is also a pipeline that is used for example the pipeline in the cloth simulation division. In the MSV studio pipeline simulation applied in the cloth simulation division there were still some obstacles during production. The work of the existing pipeline during the process of checking asset data which is still manual between Sceneres and Renderes needed for cloth simulation is still often had an error such as human error and set up cloth still done in every shot. From this problem it is proposed to develop a pipeline cloth simulation in order to minimize errors and saving time processing. The results of the production of animated films are strongly influenced by the pipeline used in the production. This studyprovides an illustration of how a pipeline contributes greatly to the results of the production of 3D animated films, especially in the matter of time. In the end, this study can be a reference in making an animation film pipeline, especially in the cloth simulation division.
\end{abstract}

Keywords - pipeline, cloth simulation, 3D animation

\section{PENDAHULUAN}

Saat ini animasi sudah sangat berkembang khususnya pada animasi 3D, mulai dari pembuatan iklan hingga film layar lebar. Potensi dari industri animasi ini menjadikan negaranegara yang industri animasinya belu tumbuh berusaha berlomba-lomba untuk mengusung industri ini sebagai salah satu kekuatan ekonomi kreatif dinegaranya. Indonesia sebagai negara 
berkembang juga mempunyai potensi yang tinggi untuk mengembangkan industri animasi. Disamping jumlah penduduk yang cukup besar, juga negara Indonesia mempunyai berbagai macam budaya yang sangat berpotensi untuk dikembangkan dalam animasi. Tren outsorce dari industri animasi besar dunia ke Asia merupakan isu yang sangat potensial bagi pengembangan kedepan animasi.

Animasi 3D memiliki tahapan proses pembuatan produksi atau yang di sebut dengan Pipeline produksi yang teridiri dari pre-production, production, dan post-production. Oleh karena itu dalam Studio animasi terdapat beberapa divisi yang sesuai dengan tahap-tahap pembuatan tersebut. Pembagian divisi tersebut bertujuan agar setiap proses pembuatan 3D animasi dapat dikerjakan dengan sangat baik. Salah satunya adalah disvisi cloth simulation. Dilihat dari tahapan pembuatan animasi yang begitu banyak, sudah pasti dalam produksi animasi membutuhkan waktu yang cukup lama. Cloth Simulation adalah salah satu divisi yang menangani simulasi kain dalam produksi animasi. Sedangkan dalam pengertianya, Cloth Simulation atau Pemodelan kain adalah istilah yang digunakan untuk mensimulasikan kain dalam program komputer, biasanya dalam konteks grafik komputer 3D.

Pemodelan 3D cloth yang berbeda material dapat dibuat dengan menggunakan parameter seperti massa, stifnes dan damping. Sistem uji coba penerapan pipeline pemindahan dan penerapan jenis kain ke body dalam berbagai bentuk dan pose dengan grade preservation. Untuk mencapai hasil yang optimal, jenis kain harus bersifat elastis dan dikontrol secara dinamik pada Gambar 1 [1].

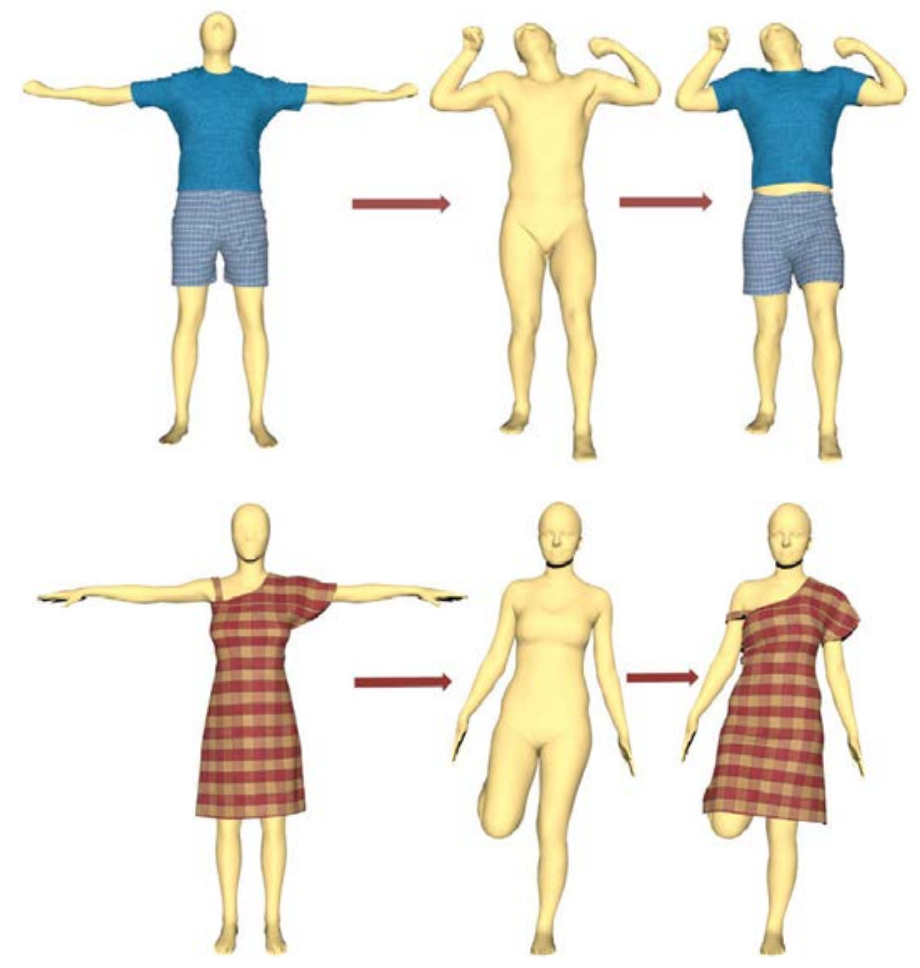

Gambar 1. Transfering kain dari body satu ke body yang lain dengan bentuk dan pose yang berbeda

Parameter yang digunakan seperti mass, stiffness dan damping sangat berpengaruh sekali dalam hasil dari simulasi. Selain itu juga penggunaan metode deformasi dan metode simulasi dalam interaksi dengan objek lain menghasilkan hasil yang lebih realis pada Gambar 2 [2]. 
Citec Journal, Vol. 7, No. 2, Juli 2020
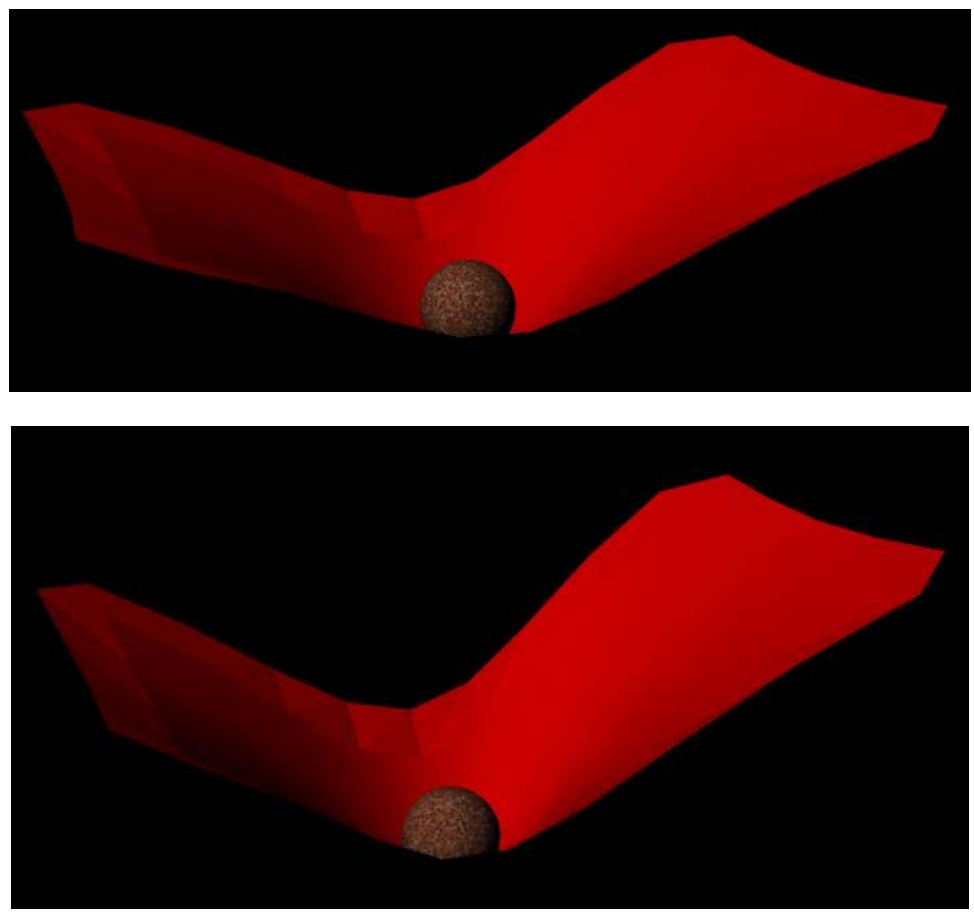

Gambar 2. Simulasi flag dengan dropping ball

Namun dalam praktiknya ketika proses simulasi kain di terapakan dalam proses animasi masih banyak terdapat kendala, baik itu dari segi teknis maupun dari segi bentuk topology mesh yang digunakan untuk simulasi kain. Dari segi teknis sendiri sebuah pipeline juga sangat mempengaruhi proses berlangsungnya simulasi pada saat produksi. Penelitian sebelumnya mengatakan proses animation pipeline dimulai dari gagasan cerita yang bisa berasal dari berbagai hal. Proses untuk mengubah ide menjadi cerita dapat mengambil dari berbagai kondisi yang berbeda. Terkadang skenario ditulis lengkap dan dikembangkan dengan cara yang sama seperti naskah untuk film live action [3].

Hasil cloth simulasi sangat dipengaruhi oleh sifat jenis kain yang diterapkan pada setiap kain dan nilai parameter yang berbeda beda pada setiap kain yang digunakan pada saat simulasi [4]. Proses animation pipeline berbeda-beda, hasil eksperimen kami menunjukkan bahwa metode pipeline ini cepat dan konvergen ke pola yang tepat dalam simulasi, membentuk target seperti yang diinginkan dan bekerja dengan baik dengan berbagai perbedaan black-box physical simulasi [5]. Penggabungan algoritma parallel collision dan response computations dijadikan patokan sebagai pipeline dari cloth simulation karena teruji membuat pengerjaan menjadi lebih efisien [6]. Penggunaan pipeline dengan menerapkan volume simulai pada mesh karakter dan selfintersection sebelum masuk ke tahapan divisi simulasi berhasil mengatasi cloth simulasi pada saat ada gerakan animasi yang lebih kompleks [7]. Menurut penelitian sebelumnya, simulasi kain juga dipengaruhi oleh adaptif mesh yang dikombinasikan dengan coarsening [8].

Pada penelitian ini mencoba mengembangkan pipeline simulasi yang sudah ada di MSV Studio karena melihat ada beberapa kelemahan di pipeline sebelumnya yang mempengaruhi proses dan hasil cloth simulation. Misalnya seperti set up cloth masih dilakukan secara manual disetiap shot animasi. ketika shot animasi siap untuk disimulasikan bagian clothnya harus set up satu persatu karakter yang ada dalam shoot tersebut. Hal ini memakan waktu yang cukup lama terutama ketika dalam shoot tersebut terdapat banyak karakter. Disamping itu ketika set up cloth sudah selesei harus disimulasikan frame by frame yang pastinya butuh waktu lebih lama untuh proses simulasinya. Di pipeline produksi animasi MSV dibagi menjadi file Renderes dan Sceneres. Sceneres file yang dipakai animator dalam menganimasikan asset 3D karakter. Sedangkan file File renderes merupakan file yang nantinya bakal masuk ke divisi render dan akan di proses setelah masuk lighting. 


\section{METODE PENELITIAN}

Penelitian ini menggunakan pendeketan penelitian deskriptif kualitatif. Langkah-langkah dalam penelitian ini mulai dari pengumpulan data melalui study literature, observasi dan wawancara. Setelah itu mulai melakukan penelitian pada produksi animasi 3D pada divisi cloth simulation. Yang akan dijadikan objek penelitian dalam hal ini adalah film animasi 3D yang sedang di produksi MSV studio. Dari produksi animasi 3D ini mulai kita evaluasi kebutuhan dan kelemahan pada pipeline yang digunakan sebelumnya. Diantaranya set up jenis cloth, kompire asset 3D yang ada pada Sceneres dan Renderes masih kurang efektif dalam prakteknya, karena memakan waktu yang cukup lama ketika pelaksanaanya. Untuk itu penulis mencoba melakukan penelitian pengembangan tools untuk mendukung pipeline cloth simulation untuk melihat memungkinkan atau tidak dalam optimalisasi pengerjaan cloth simulasi pada saat produksi film animasi 3D.

\subsection{Teknik Pengumpulan data}

Dalam penelitian ini dalam memperoleh data yang diperlukan yang pertama melalui observasi. Observasi digunakan untuk memperoleh data atau infomasi dengan mengamati secara langsung ditempat kejadian. Dalam hal ini penelitian dilakukan secara langsung dalam produksi film animasi 3D di MSV Studio. Penulis mengamati secara langsung proses, kendala dan permasalahan yang terjadi pada produksi film animasi 3D di MSV Studio pada divisi cloth simulation. Yang kedua dengan study kepustakaan atau study literatur, dalam hal ini mengumpulkan informasi sebanyak banyaknya dari kepustakan yang berhubungan dengan cloth simulation. Yang ketiga wawancara, materi wawancara mengenai kelebihan dan kekurangan pipeline yang digunakan. Dalam penelitian ini yang menjadi subjek wawancara adalah 3D artis Cloth simulation yang terlibat langsung dalam produksi film animasi 3D ajisaka.

\subsection{Teknik Analisis Data}

Langkah selanjutnya adalah melakukan analisis terhadap data yang sudah dikumpulkan sebelumnya. Analisis data yang dilakukan yaitu dengan menarik kesimpulan dari data yang telah dikumpulkan dari observasi dan wawancara terhadap artist cloth simulation. Selanjutnya menentukan data asset 3D yang dibutuhkan oleh artis cloth simulation, seperti aturan penggunaan dataAsset 3D antara file data asset Sceneres dan Renderes yang harus memiliki jumlah vertex dan face geometri yang sama. Selain itu juga memilah geometri mana yang belum sesuai dengan kebutuhan cache cloth simulation.

Data yang dihasilkan dalam penelitian ini adalah sebuah visual video film animasi 3D dari hasil dari implentasi tools pipeline cloth simulation. Untuk melihat apakah tools pipeline sudah berjalan dengan baik atau belum ketika diterapkan di divisi cloth simulation, dan berpengaruh tidak dengan timeline proses produksinya maka hasil dari film animasi 3D akan dianalisis oleh para ahli dibidang animasi 3D diantaranya, Produser, Director, Art Director, Animation Director dan Teknical Director yang terlibat langsung dalam proses produksi film animasi 3D di MSV Studio. Gambar 3 merupakan langkah-langkah yang dilakukan dalam penelitian ini. 
Citec Journal, Vol. 7, No. 2, Juli 2020

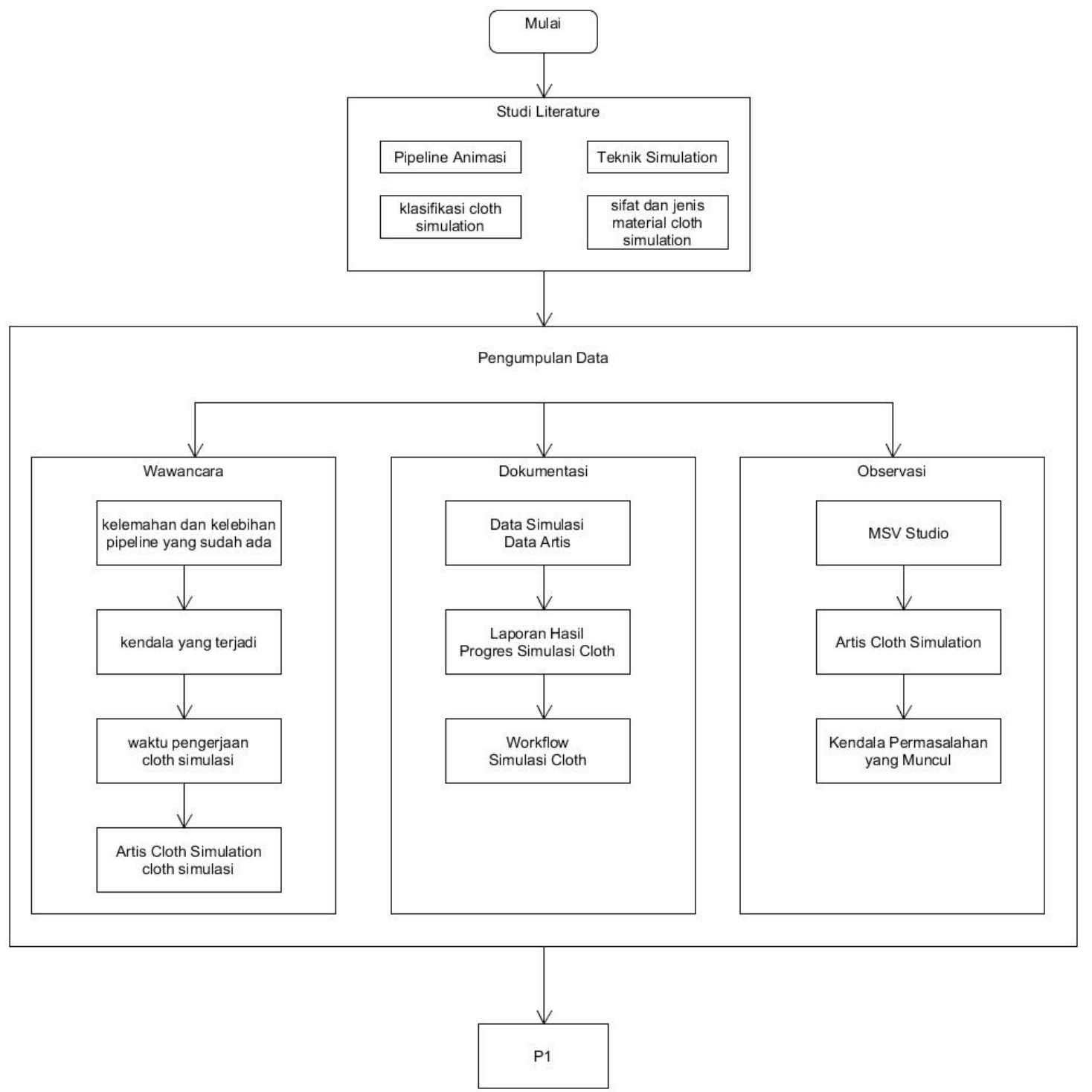

Gambar 3. Alur Penelitian 


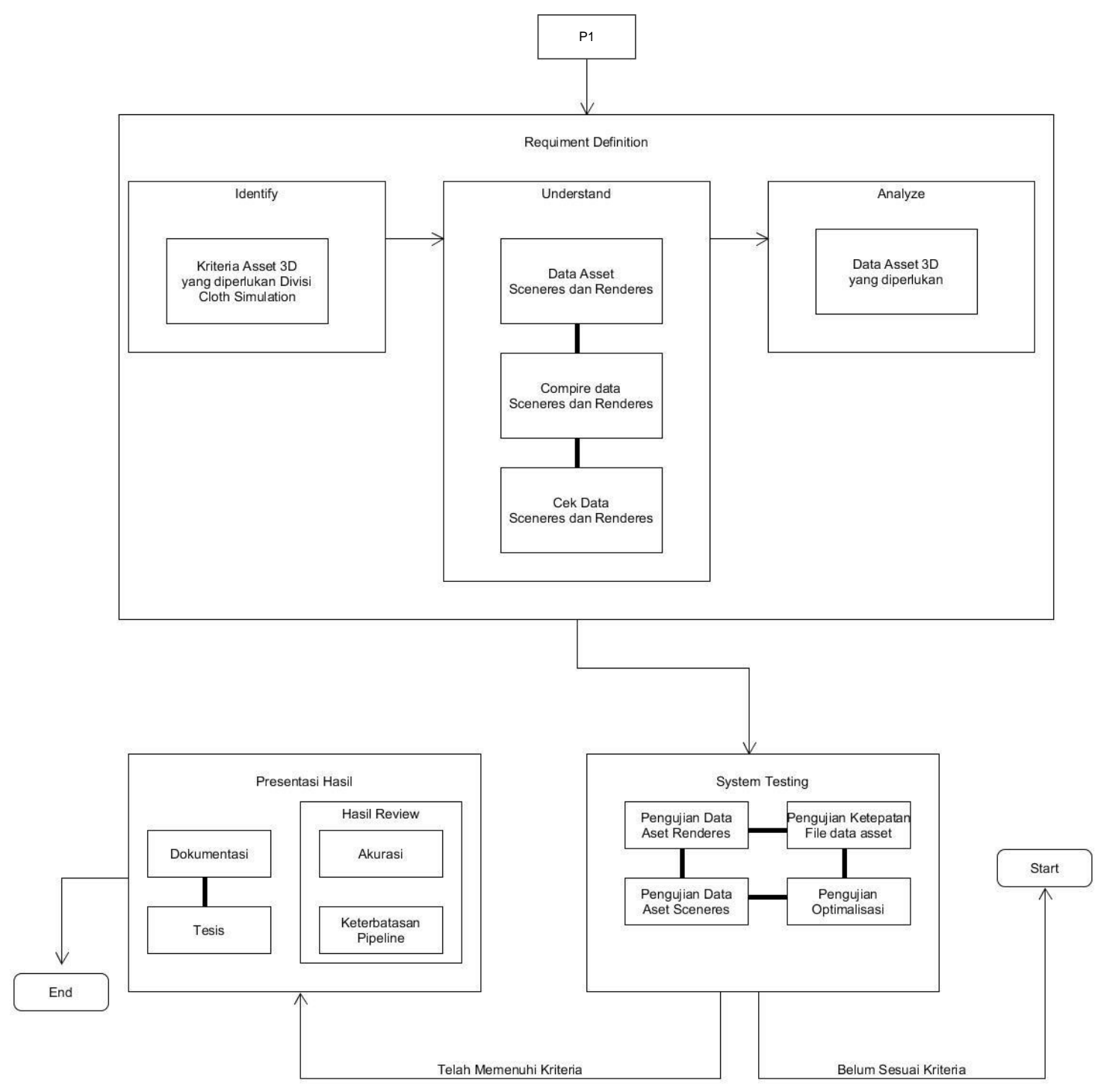

Gambar 3. (lanjutan)

\section{HASIL DAN PEMBAHASAN}

\subsection{Produksi Film Animasi}

Dalam proses pembuatan animasi dikerjakan sesuai dengan pipeline atau alur kerja yang di pakai oleh studio animasi itu sendiri. Pipeline animasi itu sendiri dimulai dari tahapan PraProduksi yang berisi tentang perancangan ide cerita kemudian memvisualikasikan ide cerita tersebut kedalam storyboard. Setelah tahapan Pra-Produksi selesai kemudian dilanjutkan ke tahap Produksi. Dalam tahapan ini menyangkut beberapa pengerjaan teknis seperti konsep art, pembuatan model karakter, animasi, simulasi sampai ke lighting dan rendering. Setelah tahap Produksi selesai kemudian tahap yang terakhir adalah tahap Pasca Produksi. Dalam Pasca Produksi meliputi compositing dan editing dari hasil di tahap produksi sampai menjadi animasi yang siap tayang [9]. Gambaran umum pipeline animasi 3D seperti Gambar 4. 
Citec Journal, Vol. 7, No. 2, Juli 2020

\section{PRE-PRODUCTION}
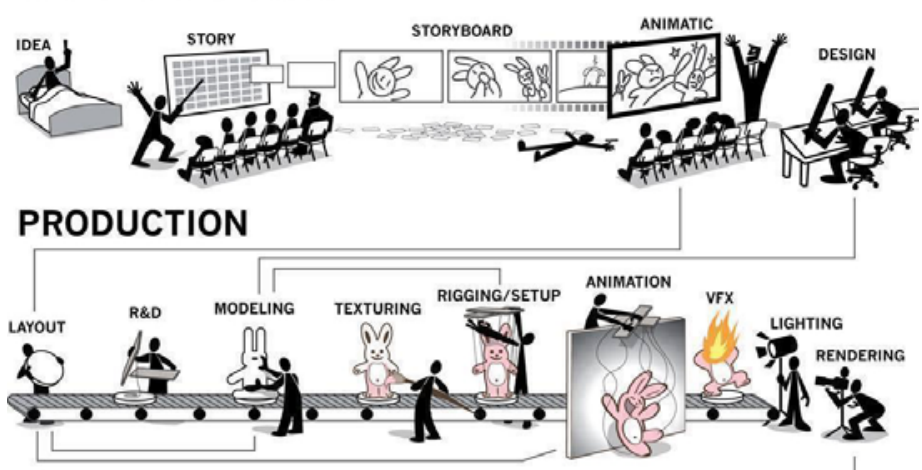

\section{POST-PRODUCTION}

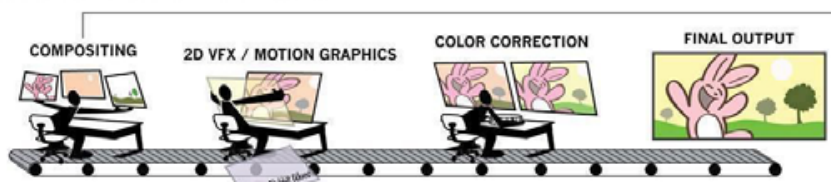

Gambar 4. Pipeline Animasi 3D

3.2. Analisis Pengembangan Pipeline Cloth Simulasi

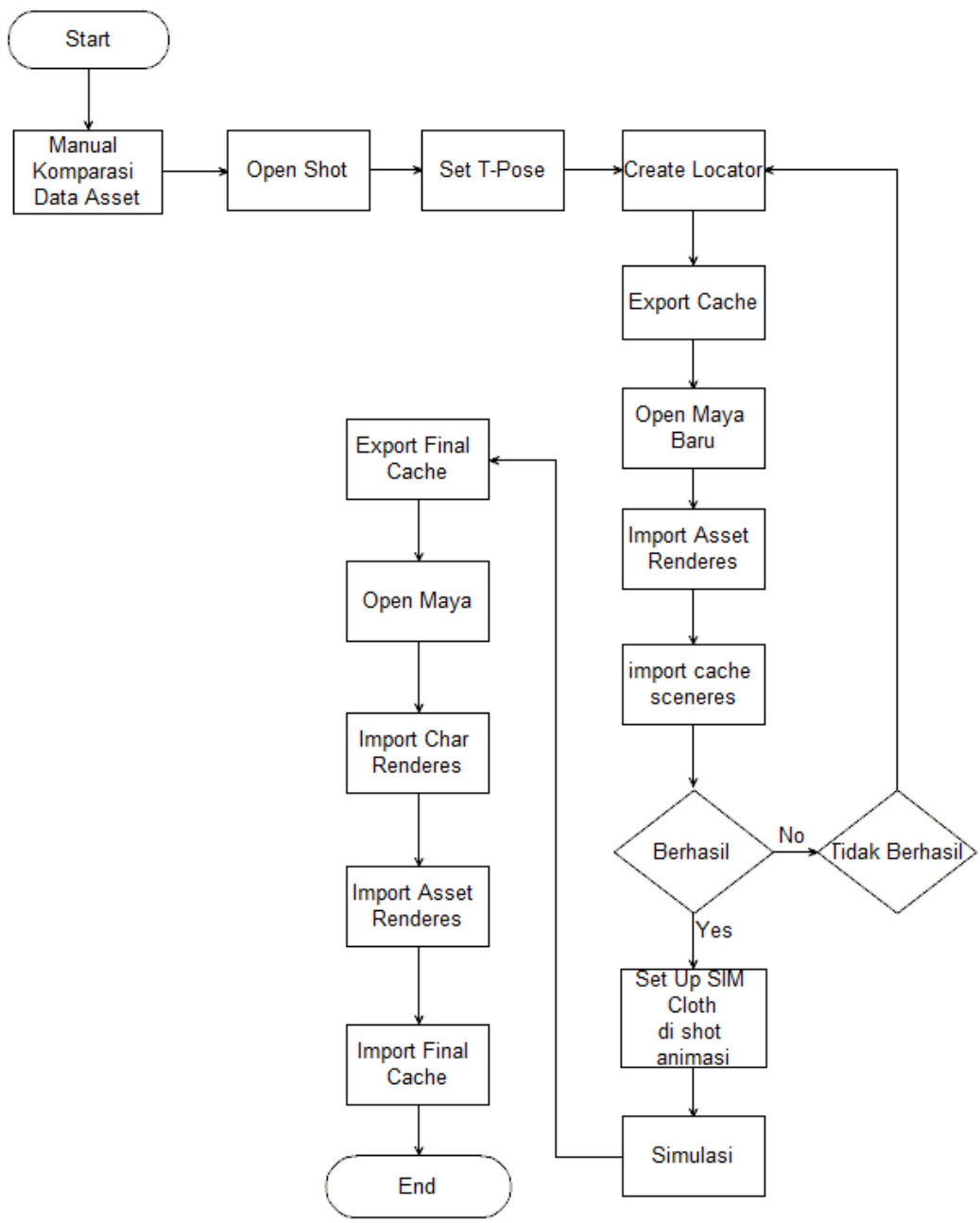

Gambar 5. Pipeline Awal Cloth Simulation 
Setiap divisi dalam produksi film animasi 3D mempunyai pipeline per bagianya. Hal ini bertujuan agar pengerjaan produksi film animasi bisa berjalan sesuai jadwal yang telah direncanakan. Penelitian dilakukan pada divisi cloth simulation pada MSV Studio. Divisi cloth simulation sendiri mempunyai pipeline sendiri untuk mendukung pipeline pruduksi yang ada di MSV Studio agar bisa efektif. Pipeline simulasi cloth sendiri bertujuan digunakan untuk acuan atau standar pengerjaan cloth simulasi agar bisa efektif dan efisien saat pengerjaanya. Pipeline awal cloth simulasi dapat dilihat pada Gambar 5.

Pengujian tahap pertama dalam pipeline simulasi yang diterapkan sebelumnya yaitu dengan tingkat ke efektifan ketika proses Set Up cloth simulation. Dalam proses penerapan Set Up cloth simulation masih dilakukan pada setiap shot yang telah dianimasikan. Setiap asset karakter memiliki jumlah varian cloth yang berbeda-beda. Berikut ini sample beberapa pengujian yang dilakukan:

1. Pengujian yang pertama yaitu dengan melakukan set up cloth disetiap shot. Set up dilakukan oleh artis cloth simulation dengan satu karakter dalam satu shot dengan 3 varian cloth.

2. Pungujian kedua dengan melakukan set up cloth dengan 1 karakter dengan varian cloth lebih dari 3 varian dalam satu karakter.

3. Pengujian ketiga dengan melakukan beberapa karakter sekaligus di satu shoot.

Pengujian sample tersebut dapat dilihat pada table 1 berikut:

Tabel 1. Sample pengujian set up cloth dalam 1 shoot

\begin{tabular}{ccc}
\hline $\begin{array}{c}\text { Jumlah Karakter } \\
\text { dalam } 1 \text { shoot }\end{array}$ & $\begin{array}{c}\text { Jumlah Varian } \\
\text { Cloth }\end{array}$ & $\begin{array}{c}\text { Estimasi Waktu } \\
\text { Set Up }\end{array}$ \\
\hline 1 & 3 & $5-8$ menit \\
\hline 1 & 4 & 9 menit \\
\hline 2 & 7 & $13-15$ menit \\
\hline 2 & 8 & 15 menit \\
\hline
\end{tabular}

Ketika proses Set Up ini berlangsung memerlukan waktu yang lama sekitar 5 sampai 8 menit disetiap karakternya tergantung dari berapa varian cloth yang ada di setiap asset 3D. Proses ini sangat memungkinkan akan lama ketika dalam satu shot terdiri banyak karakter yang harus di set up satu persatu. Disamping itu ketika proses simulasi berjalan, prosesnya frame by frame atau bisa dikatakan lama simulasi tergantung berapa jumlah frame dalam satu shot animasi. Proses set up cloth asset karakter dalam setiap shot ditunjukan pada Gambar 6.

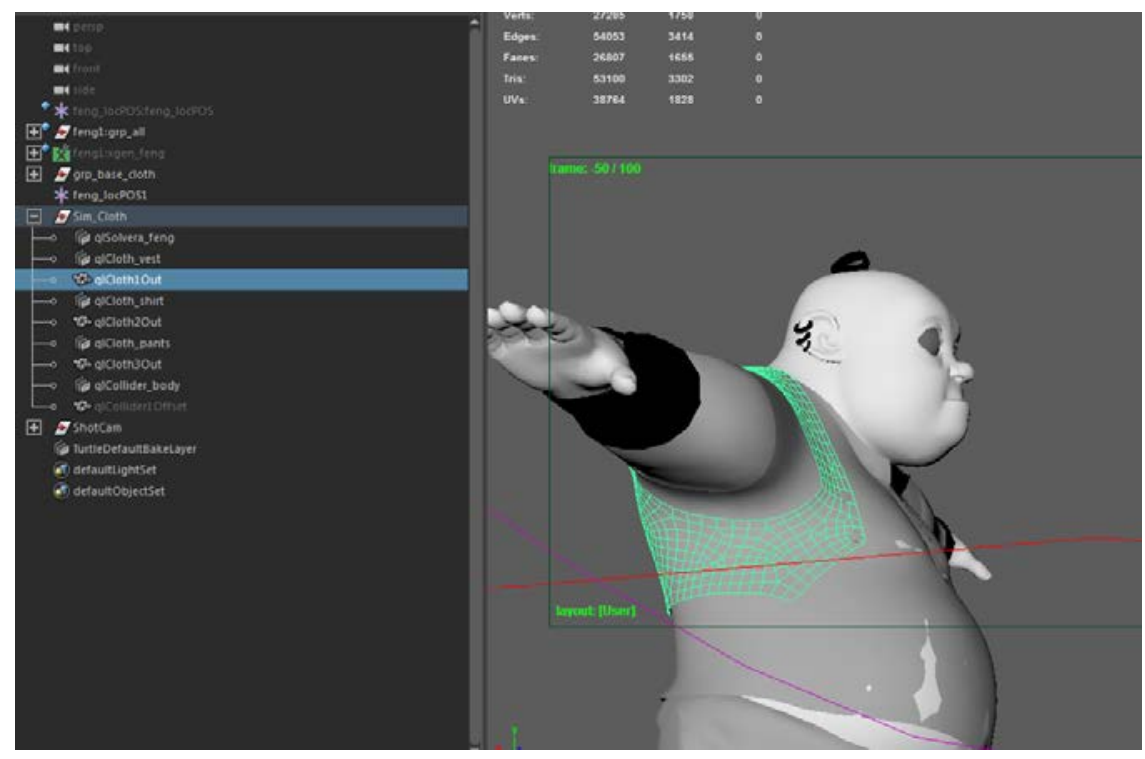

Gambar.6 Set up Cloth dalam shot 
Pengecekan data asset diperlukan agar 3D model yang sudah dianimasikan ketika dicompire dengan data Asset yang akan disimulasikan sesuai dan file cache dari pergerakan animasi tersebut sehingga bisa dipakai ke data asset cloth simulasi. Di pengecekan ini setiap data asset 3D di cek dari segi penamaan hirarki geometry, kemudian kesesuaian jumlah vertex dan set grup. Create locator bertujuan untuk membantu memindah posisi objeck geometry agar posisi sesuai dengan posisi saat pengambilan camera di setiap shotnya.

Kemudian dalam setiap export dan import file cache baik itu cache action atau final cache yang didapat dari rekaman gerakan animasi, ketika di export harus membuat folder secara manual. File Cache Action merupan file Geometry cache dari geometry yang sudah di animasikan. Proses import file cache dapat dilihat pada Gambar 7.

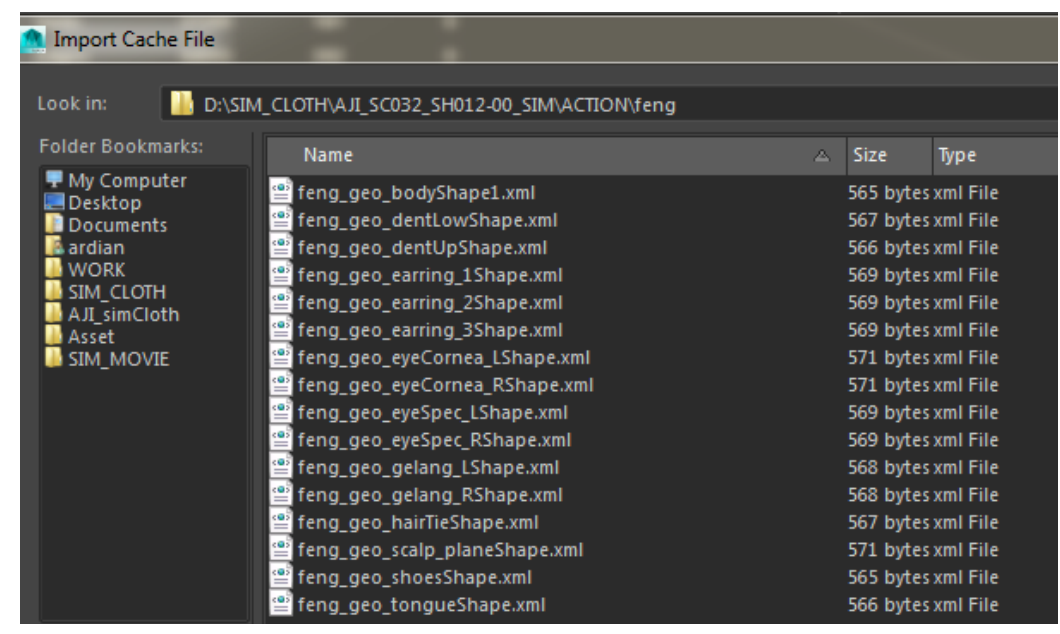

Gambar 7. Import file Cache

File Final Cache merupakan file Geometry keseluruhan yang sudah melalui proses simulasi Dalam setiap shot animasi terdapat beberapa folder seperti Folder Action, Folder SIM, Folder Scene, Folder Final Cache, dan Folder Temp. Folder Action dipakai untuk menyimpan file geometry Cache yang diambil dari asset yang telah dianimasikan.

1. Folder SIM digunakan untuk menyimpan file cache simulasi cloth.

2. Folder Scene digunakan untuk menyimpan file scene maya.

3. Folder Final Cache digunakan untuk menyimpan keseluruhan file geometry cache yang sudah selesai proses simulasinya.

4. Folder Temp digunakan untuk menyimpan file locator, camera dan back up file cache.

5. Folder tersebut dibuat agar proses penyimpanan file setiap shot dapat tersusun dengan baik. Disamping itu juga memudahkan manajemen file yang rapi. Jadi ketika sewaktu waktu terdapat revisi dalam satu shot di karakter tertentu, maka tinggal update karakter yang direvisi saja misal file geometry cache action. Pembuatan folder tersebut seperti pada Gambar.8.

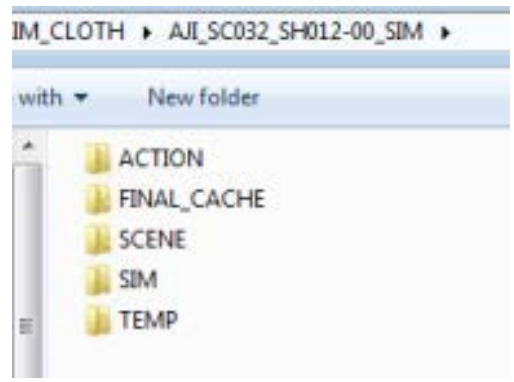

Gambar 8. Pembuatan Folder 


\subsection{Hasil Analisis}

Melihat Pipeline cloth simulation yang di terapkan pada divisi cloth simulation terdapat kekurangan yaitu masalah efisiensi waktu pengerjaan set up cloth simulation. Proses set up cloth simulation dalam setiap shot dapat mempengaruhi durasi simulasi pada setiap shot.

Dari pemngamatan pipeline awal, akan dibuat file baru yaitu file SIM. File SIM tersebut mengambil dari File Renderes yang kemudian di setiap Asset Renderes yang akan di simulasikan di set up terlebih dahulu dalam setiap file tersebut. Set up setiap data asset ini dimaksudkan agar ketika proses simulasi berlangsung tidak perlu set up lagi disetiap shot animasi. Karena diawal sudah diset up dan nantinya langsung di jalanankan proses simulasinya. Disamping itu cara ini dapat memberi kemudahan kepada artis cloth simulasi karena tidak perlu set up cloth di setiap shot animasi. Gambar 9 merupakan proses set up cloth per karakter atau file SIM.

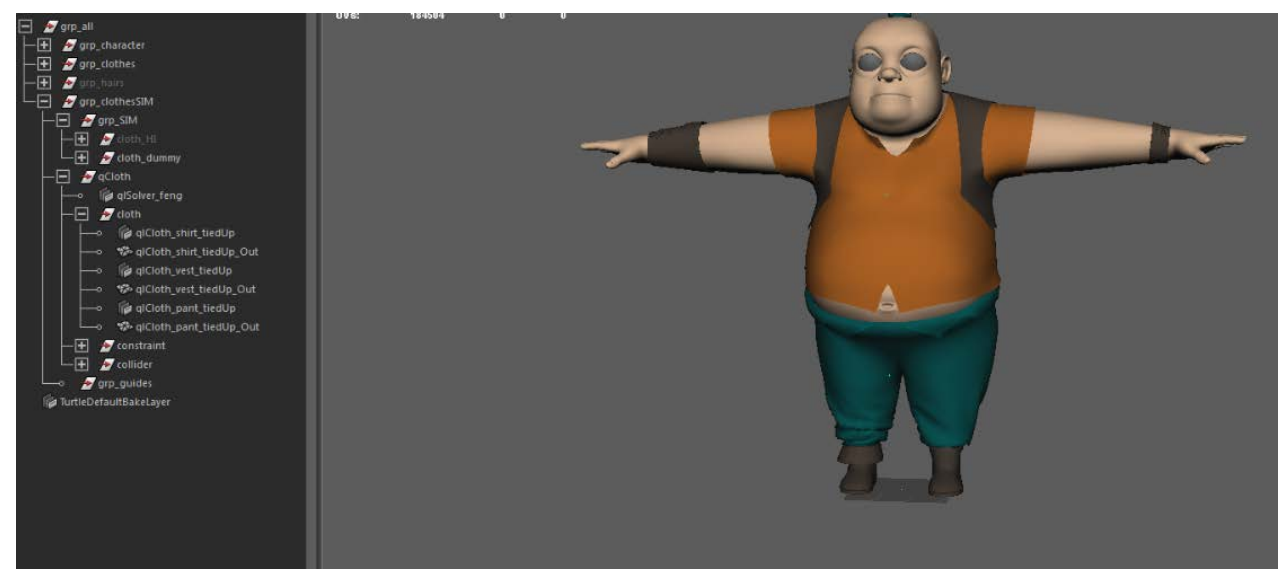

Gambar 9. Proses set up file SIM

Proses export geometry cache dan final cache dilakukan secara otomatis menggunakan anim cache tools dari pengembangan pipeline sebelumnya. Selain itu juga pembuatan locator dan pembuatan folder dilakukan secara otomatis. Pengembangan pipeline yang dilakukan seperti pada Gambar 10.

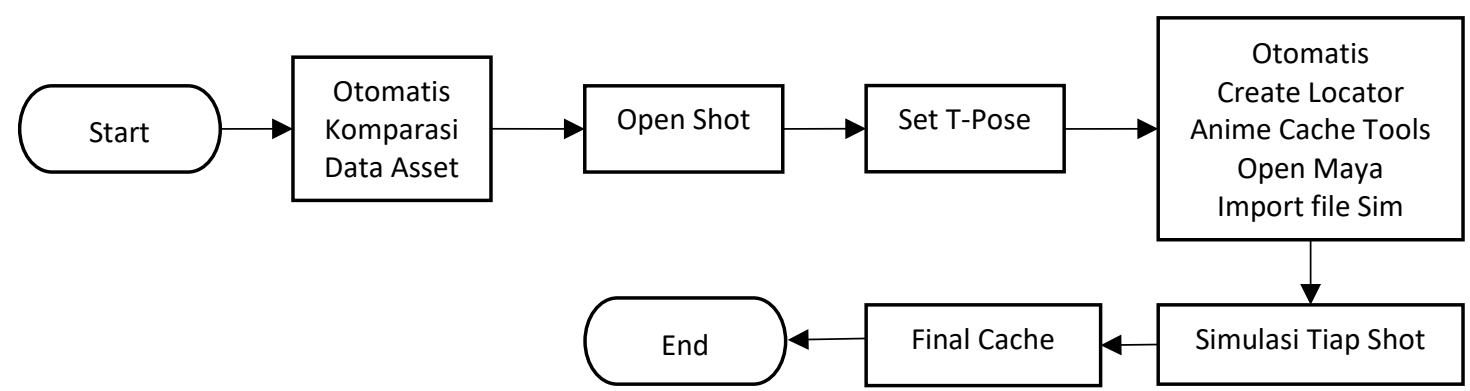

Gambar 10. Pipeline Baru Cloth Simulation

Dari pipeline baru tersebut bisa di terapkan dan digunakan oleh divisi cloh simulation untuk membantu mempercepat proses simulasi di setiap shotnya. Yang semula memakan waktu sampai 8 menit untuk proses set up clothnya dalam satu karakter, sekarang tinggal import file SIM kemudian masukan cache action dan langsung bisa dijalankan simulasinya. Penerapan seperti pada Gambar 11. 
Citec Journal, Vol. 7, No. 2, Juli 2020

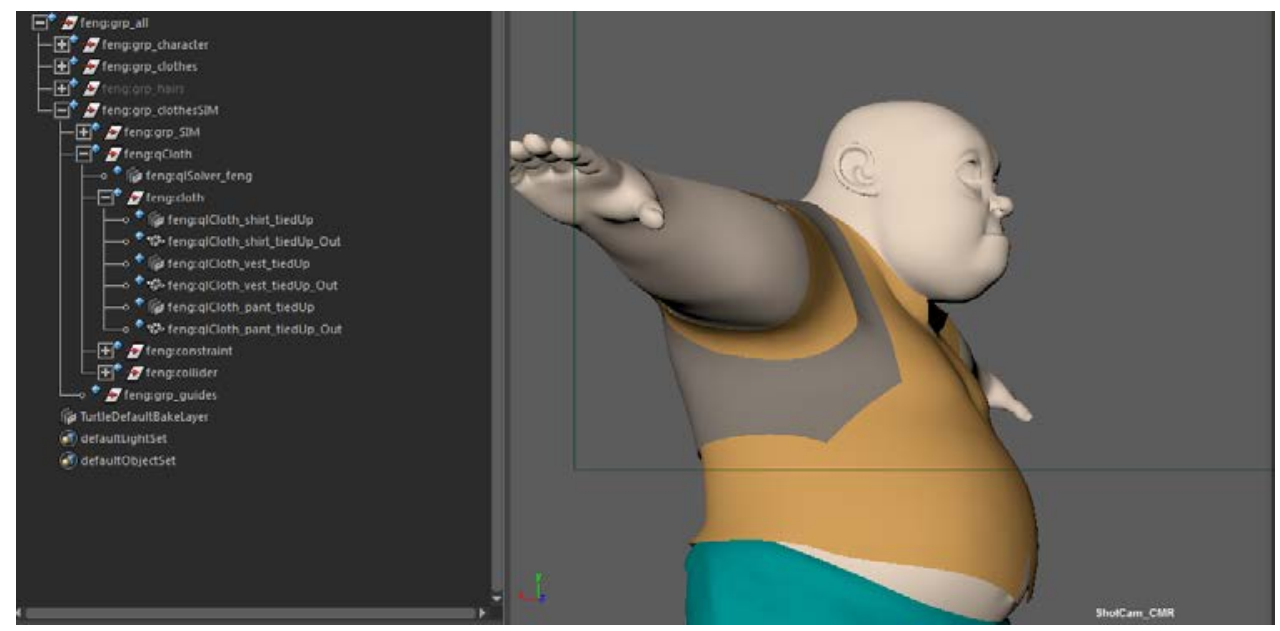

Gambar 11. Import File SIM dalam shot

Setelah melakukan pengujian terdapat pipeline baru, ternyata pipeline tersebut bisa sangat membantu artis cloth simulation. Baik ketika melakukan set up maupun proses simulasi. Hal tersebut juga di dukung oleh Supervisor divisi cloth simulation yang telah meriview pipeline baru yang diusulkan. Mengatakan bahwa pipeline baru untuk cloth simulation sangat membantu dalam efisiensi waktu pengerjaan cloth simulation.

\section{KESIMPULAN}

Dari hasil analisis mengenai pipeline simulasi cloth maka dapat diambil beberapa kesimpulan dari hasil yang di dapat dari studi ini, diantaranya yaitu:

1. Proses export import geometry cache lebih cepat karena dibuat otomatis.

2. Proses set up cloth dilakaukan disetiap data asset yang akan disimulasi jauh lebih mudah karena set up nya tidak di setiap shotnya melainkan hanya di file data asset SIM saja.

3. Dapat mempermudah artis cloth simulasi dalam melakukan proses set up dan menjalakan simulasi di setiap shotnya.

4. Tidak perlu membuat folder setiap shot satu persatu karena sudah otomatis.

5. Pengerjaan simulasi lebih cepat karena karena tidak perlu set up lagi disetiap shotnya.

\section{SARAN}

Berdasakan kesimpulan ada beberapa saran yang perlu dilakukan dalam penelitian, diantaranya yaitu:

1. Semakin banyak pengujian dilakukan selain di MSV Studio, maka akan mendapatkan hasil lebih baik terhadap hasil sebelumnya.

2. Ruang lingkup diperbesar selain di MSV Studio.

\section{DAFTAR PUSTAKA}

[1] Jiang, L., Ye, J., Sun, L., Li, J., 2019, Transfering and Fitting Fixed-sized garment onto bodies of varios dimension and Posture, Computer-Aided Design, Vol. 106, Hal. 30-42

[2] Ho, T., 2016, Cloth-Modeling, Deformation, And Simulation, California State University, San Bernardino. 
[3] Milligan, M., 25 Juli 2019, Andrea Miloro Exits Fox Animation Co-President Post, https://www.animationmagazine.net/people/andrea-miloro-exits-fox-animation-copresident-post/ Diakses pada tanggal 18 Maret 2020.

[4] Nagarth N., 2016, Implementation of Cloth Simulation that can be Used in Games and Animation, Dissertation, University of Dublin, Trinity College.

[5] Bartle, A., Sheffer, A., Kim, V.G, Kaufman, D.M., Vining, N., Berthouzoz, F., 2016, Physicsdriven Pattern Adjustment for Direct 3D garmen editing, ACM Journal, Vol.35 , Hal. 1-11.

[6] Tang, M., Wang, H., Tang, Le., Tong, R., Manocha, D., 2016, Contact-Aware Matrix Assembly with Unified Collision Handling for GPU-based Cloth Simulation, http://gamma.cs.unc.edu/CAMA/. Diakses pada tanggal 10 April 2020.

[7] Wong, A., Eberle, D., Kim, T., 2018, Clean Cloth Inputs: Removing Character SelfIntersections With Volume Simulation, Conference: ACM SIGGRAPH 2018 Talks, New York, August 18.

[8] Rao, A., Bayyapu, N., 2018, Effective Algotihm for improving the Performance of Cloth Simulation, National Conference on Emerging Trends in Computer Engineering \& Technologies, Tamil Nadu - India, 5 - 6 April 2018

[9] Beane, A., 2012, 3D Animation Esentials, ED.1, Sybex Inc. John Wiley \& Sons, Hoboken US. 